\title{
Approaches to solve cell formation, machine layout and cell layout problem: A Review
}

\author{
J. N. Patel ${ }^{1}$, S. V. Patel ${ }^{2}$ \\ ${ }^{1}$ Chhotubhai Gopalbhai Patel Institute of Technology, Uka Tarsadia University, Surat, Gujarat, India \\ ${ }^{2}$ Computer Science Department, Veer Narmad South Gujarat University, Surat, Gujarat, India \\ ce6_jigar@yahoo.co.in; patelsv@gmail.com
}

\begin{abstract}
Cell formation, machine layout and cell layout problems in cellular manufacturing system are NPComplete optimization problems. Good cell formation \& layout design in cellular manufacturing system is achieved by finding optimum or near-optimum solutions of these problems, which substantially reduces manufacturing cost and time. Many approaches have been advocated by researchers to obtain better cell formation \& layout design. An attempt has been done in this paper to review such approaches based on heuristics, meta-heuristics, hybrid methods and exact solution methods developed by past researchers to solve these problems. The main objective of this review paper is to find out the effective and efficient approaches by comparing them based on performance criteria, their benefits and drawbacks in solving cellular manufacturing system problems and find out future research scope in this area.
\end{abstract}

Keywords: Genetic Algorithm, Cell Formation Problem, Machine Layout Problem, Cell Layout Problem.

\section{Introduction}

Frederick Taylor introduced group technology as a manufacturing philosophy that improves productivity by grouping parts with similar characteristics into part-families and creating production cells with a group of dissimilar machines. Cellular manufacturing uses the principles of group technology to achieve higher production efficiency compared to traditional manufacturing so as to create factory and shop floor layout design. Cellular manufacturing can be implemented in four stages as per the following.

1. Cell formation: Grouping parts into part families and corresponding machines into machine cells by using the parts production process.

2. Intra-cell layout: Layout of machines within each cell.

3. Inter-cell layout: Layout of cells within the factory or shop floor.

4. Scheduling: Scheduling of jobs in each cell.

Advantages of cellular manufacturing compared to traditional manufacturing by efficient layout design reported in the literature are as per the following.

1. Reduced production lead time

2. Reduced setup time

3. Reduced work-in-process

4. Reduced material handling cost

5. Reduced flow distance of material 
6. Reduced lot sizes

7. Reduced throughput times

8. Reduced tooling cost

9. Reduced labour cost

10. Reduced production equipment cost

11. Improved machine utilization

12. Simplified process planning

13. Better worker morale

14. Improved quality

Cell formation, machine layout and cell layout problem in cellular manufacturing system are known to be NP-Complete optimization problems. Exact solution methods are inefficient for solving these large-sized NP-Complete problems. So researchers have developed heuristics, meta-heuristics and hybrid methods to solve these large-sized NP-Complete problems efficiently. Appropriate performance criteria to be selected by past researchers to compare performance of their approach or approaches with other existing approaches to solve cell formation problem are grouping efficiency [1, 2], grouping efficacy [3], comparison with optimum solution [4], machine utilization [1], number of inter-cellular moves [5], bond energy [6], percentage of exceptional elements [7], number of non-dominated solutions [8], quality metrics [8], hyper area ratio metric [8], relative metric [8], spacing metric [8], cell flow index [9], overall flow index [9], average cell flow index [9]. Appropriate performance criteria to be selected by past researchers to compare performance of their approach or approaches with other existing approaches to solve machine layout problem are percentage of variation with optimum solution [10,11], total distance travelled by all parts [12], price of a layout [13], cell flow index [9], average cell flow index [9]. Appropriate performance criteria to be selected by past researchers to compare performance of their approach or approaches with other existing approaches to solve cell layout problem are total inter-cell material handling distances [14], percentage of deviation with best-known solution [14], overall flow index [9].

This paper discusses comparative analysis of approaches to solve these problems done by researchers available in past. Better approach to be found based on average performance in past papers is also suggested in this paper.

The rest of the paper is organized as follows: Section 2 describes cell formation, machine layout and cell layout problem in cellular manufacturing system. Section 3 presents review \& comparison of approaches such as heuristics, meta-heuristics, hybrid methods and exact solution methods taken from literature to solve cell formation, machine layout and cell layout problem in cellular manufacturing system. Analytical review of approaches is presented in Section 4. Conclusion and future scope is mentioned in Section 5.

\section{Cell formation, machine layout and cell layout problem}

Cell formation problem: the process of grouping parts with similar design features or processing requirements into part families and the corresponding machines into machine cells so as to maximize grouping efficiency and grouping efficacy.

Machine layout problem: consider $m$ machines and $n$ parts are used during the manufacturing of a various kinds of products in Cellular Manufacturing. Various parts are processed by a machine and a single machine may often be utilized during the manufacturing of a various kinds of products. Objective is to decide an optimal layout scheme of all $m$ machines in a way that minimizes total traveling distance of all 
J. N. Patel, S. V. Patel; Approaches to solve cell formation, machine layout and cell layout problem: A Review,

Transactions on Machine Learning and Artificial Intelligence, Volume 2 No 5 Oct (2014); pp: 80-96

$\mathrm{n}$ parts, so substantially reduces total manufacturing costs for manufacturing industries, subject to no overlap and no duplication of machine constraints.

Cell layout problem: layout of cells within the factory or shop floor in a way that minimizes the inter-cell movement of various parts.

\section{Approaches to solve cell formation, machine layout and cell layout problem}

\subsection{Heuristics}

Heuristics use domain-specific knowledge to solve large-sized NP-Complete problems efficiently. They may or may not produce optimum solution of the problem. But good heuristics may produce near optimum solution of the problem.

\subsubsection{Effective non-iterative sorting method}

An effective non-iterative sorting method was developed to solve facility layout problem in [15]. This method is capable of obtaining solutions that are not too far from the optimum and also provides a base for improvement methods. It needs to be refined further such that it becomes capable to solve facility layout problem having different shapes and sizes of facilities. It also needs to be extended to find out optimum solution of facility layout problem.

\subsubsection{Interactive hierarchical design approach}

An interactive hierarchical design approach was developed to solve cellular layout problems in [16]. Numerous example problems were taken from the literature to test this approach. The comparison demonstrated that this approach finds out generally more efficient layouts.

\subsubsection{Heuristic algorithm}

A heuristic algorithm was developed in [11] to solve machine layout problem in cellular manufacturing system. The solutions generated by heuristic algorithm were compared with the optimum solutions \& from comparison it was found that average percentage of variation of results generated by heuristic algorithm with optimum is $4.78 \%$ in evaluated cases. So this heuristic algorithm is able to find out the very good solution, outperforms solution techniques described in [15] in all five cases taken from [15] and outperforms solution technique described in [16] in three cases out of five cases taken from [15].

\subsubsection{Novel construction-cum-improvement heuristic}

A novel construction-cum-improvement heuristic was developed in [12] to solve layout formation problem of type QAP. The novel construction-cum-improvement heuristic is capable of obtaining suboptimal solution of the test problem and outperforms other solution techniques described in [15], [16] and [11] except in period 1. For period 1, an interactive hierarchical design approach developed in [16] outperforms other solution techniques described in [15], [11] and [12]. A robust layout procedure was also recommended for dynamic environment in [12], which uses a layout constructed from an expected demand situation or expected flow matrix. 


\subsubsection{Linear assignment algorithm}

A linear assignment algorithm was developed in [7] to create machine cells and part families in cellular manufacturing systems. The bond energy, percentage of exceptional elements, the machine utilization, grouping efficiency, grouping efficacy were used as performance criteria \& many existing data sets were taken from literature to compare this linear assignment algorithm with other methods taken from the literature. The results generated by linear assignment algorithm were found almost the same as, equivalent to, or better than the best-known results. The results generated by present linear assignment algorithm were found identical to the best-known results in terms of the five performance criteria in 11 out of the 20 test problems taken from the literature. While in the remaining 9 test problems, the ratio of better performance criteria between the present results and the best-known results taken from the literature was found as 5:4. The results generated by linear assignment algorithm were found dominantly superior in terms of percentage of exceptional elements and bond energy.

The results generated by linear assignment algorithm were compared with the results generated by two commonly used heuristics, ROC [17] and GRAFICS [18]. The results generated by linear assignment algorithm were found extremely better than the results generated by ROC in terms of all five performance criteria. The results generated by linear assignment algorithm were found same as generated by GRAFICS in seven out of the 17 test problems. In the remaining 10 test problems, the ratio of better performance criteria between the linear assignment algorithms and GRAFICS was found as 8:2. This linear assignment algorithm found better solutions compared to both heuristics in terms of machine utilization, grouping efficiency and grouping efficacy.

\subsubsection{Similarity coefficient methods}

The performance comparison of 20 well-known similarity coefficient methods was presented in [19] to solve 214 cell formation problems which are either taken from the literature or created intentionally. Nine performance measures were used to assess the goodness of solutions. Based on comparison, the performance of Jaccard, Sorenson, and Sokal and Sneath 2 coefficient method was found as best [19]. Jaccard was found as most stable similarity coefficient method [19]. Hamann, Simple matching, Rogers and Tanimoto, and Sokal and Sneath coefficient method was found as inefficient under all conditions, thus not recommendable to solve cell formation problems [19].

\subsubsection{Reduced integer programming}

Reduced Integer Programming, Ant Colony Optimization \& Simulated Annealing were developed in [13] to solve machine layout problem. It was observed in [13] that it is very difficult to find out very good solutions of machine layout problem using RIP because RIP puts the machines in a hexagonal graph and does not consider machine sizes into account. The solution quality of ACO is up to $12 \%$ better than RIP. Running time of ACO is high compared to RIP. But running time of ACO can be reduced by implementing parallel ACO running on multiple processors. So it was recommended in [13] to choose ACO over RIP to solve machine layout problem. Solution quality and running time of ACO found better compared to SA on small input size of machine layout problem with 8 to 12 machines. Solution quality and running time of SA exceeded by far compared to ACO when number of machines considered in a problem is 25 . It is possible to improve the solution quality of ACO by increasing number of iterations and ants [13]. But the running time of $A C O$ is proportional to both the amount of ants and the number of iterations; this would increase the running time of ACO significantly [13]. 
J. N. Patel, S. V. Patel; Approaches to solve cell formation, machine layout and cell layout problem: A Review, Transactions on Machine Learning and Artificial Intelligence, Volume 2 No 5 Oct (2014); pp: 80-96

When solving the flexible machine layout problem, the Silver-meal lot size algorithm and brute force method of finding the right time to change the layout were expressed in [13]. A limitation to these methods is that future demands are not considered when finding solutions. So a new approach to solve this problem needs to be developed [13].

\subsubsection{SAW \& TOPSIS methods}

Multiple attribute decision making (MADM) concept was used in [20] \& cell formation, machine layout and cell layout problem were solved in cellular manufacturing system using a two-stage method in [20]. Initial solution was obtained by TOPSIS and then it was improved by SAW (TOPSIS-IMP-SAW) and TOPSIS (TOPSIS-IMP-TOPSIS) in [20]. The results of this method were compared with well-known approaches available in literature. These comparisons showed that this method offers good solutions for the CMS problem. The grouping efficiency and the grouping efficacy were used as a measure to compare the goodness of methods. "TOPSIS-IMP-SAW" method is better than the "TOPSIS-IMP-TOPSIS" method to solve small scale problems [20]. "TOPSIS-IMP-TOPSIS" method is better than the "TOPSIS-IMP-SAW" method to solve large scale problems [20].

\subsection{Meta-heuristics}

Meta-heuristics is a framework of heuristics used to update a set of solutions during a search. A number of points at once are searched by meta-heuristics rather than a single point to find out the solution of the problem. They perform more powerful search because they have mechanism which escapes them from trapping into a local minimum.

\subsubsection{Genetic algorithm}

Two Genetic algorithms were developed in [21] to solve single-row machine layout problems \& multi-row machine layout problems in cellular manufacturing system. Genetic-based approaches are able to find out good solutions in reasonably short computational time compared to using enumerative approaches. The advantage of genetic algorithm [21] is that the solution of machine layout problem can be generated using a minimum amount of data giving a benefit in a situation where cost occurred per distance of movement is not known.

A nonlinear integer model of cell formation problem in dynamic condition was first developed in [4] and then solved by Genetic Algorithm, Simulated Annealing and Tabu Search. Simulated Annealing found the better near-optimal solutions in shorter average computational times than Genetic Algorithm and Tabu Search in most of the test problems. It was reported in [4] that if the dimension of machine $x$ part matrix is greater than $10 \times 10$ and the number of cells is greater than 3 and the number of periods is greater than 2 , then Lingo 6 cannot find any solution experimentally for the presented dynamic model. It was also reported in [4] that in general, by improving and developing the GA operations, the chance of finding optimal solution will be increased, because these operations can also be used for generating neighboring solutions in Simulated Annealing, Tabu Search and in any other similar meta-heuristic approach.

In [10], a model was developed for the machine layout problem in cellular manufacturing system with the objective of minimizing total distance travelled by all parts \& Genetic Algorithm was implemented to solve the problem. The computational results from [10] show that the GA is capable of obtaining near optimal (99\%) solution of the test problem and outperforms other solution techniques described in [15], [16] and 
[11]. Also GA convergence analysis was performed in [10] to find out the number of generations in which GA converges to a near optimum or optimum solutions for five different periods. All the machine locations are considered to be of equal size in [10]. This work may be extended by considering the machine locations of unequal size.

A genetic algorithm was proposed in [22] to solve the real-sized cell formation problem. Numerical examples show that genetic algorithm is efficient and effective in searching for optimal solutions. 22 problems were selected from the literature and grouping efficacy was used as a measure to test and compare the performance of genetic algorithm with ZODIAC method [23], GRAFICS [24], GATSP-Genetic algorithm [25], GA-Genetic algorithm [26], EA-evolutionary algorithm [27], SA-simulated annealing [28]. The grouping efficacy of the solution found by genetic algorithm [22] is either better than that of other methods or it is equal to the best one in all 22 benchmark problems. In six benchmark problems, the grouping efficacy of the solution found by genetic algorithm [22] is better than that of all other methods. The best solutions for these six benchmark problems are reported for the first time in [22]. In eleven benchmark problems, the solution found by genetic algorithm [22] is as good as the best available solution in the literature. In five benchmark problems, the grouping efficacy of the solution found by all the methods are reported same in [22].

\subsubsection{Grouping genetic algorithm}

A Grouping Genetic Algorithm (GGA), a special class of genetic algorithms, heavily changed to suit the structure of grouping problems was developed in [29] to solve the cell formation problem. The fundamental advantage of this GGA is that it is able to solve the problem of large input size thus an engineer can use it as a powerful tool to decide a best plant layout from a number of different plant layout options in a short computation times. GGA is applicable to solve industrial problems and it is not trapped in local optima like heuristics [29].

A cell formation-grouping genetic algorithm was developed in [30] to solve cell formation problem. Grouping efficiency \& grouping efficacy were used as a measure to compare a grouping genetic algorithm with other methods taken from literature. Cell formation-grouping genetic algorithm outperforms ZODIAC [23] on five of the six data sets, and matches its performance on the sixth when grouping efficiency was taken as a comparison measure. Cell formation-grouping genetic algorithm found the solutions with $17 \%$ average improvement compared to ZODIAC. Cell formation-grouping genetic algorithm found the solutions with average improvement of $43 \%$ compared to ZODIAC, $2.85 \%$ compared to GRAFICS [24] and $1.5 \%$ compared to algorithm [31] when grouping efficacy was taken as a measure of effective of solutions. When grouping efficacy was taken as a measure of effective of solutions, Genetic Algorithm [32] outperformed cell formation-grouping genetic algorithm by $8.1 \%$ on one data set and by $0.3 \%$ on another out of five test data sets. For other three test data sets, Genetic Algorithm matched its performance with cell formation-grouping genetic algorithm. Genetic Algorithm slightly outperformed cell formationgrouping genetic algorithm on two test data sets out of five test data sets, but it requires more number of generation to find out the solutions compared to cell formation-grouping genetic algorithm.

An adapted grouping genetic algorithm was developed in [5] to solve a generalized cell formation problem in cellular manufacturing system. Four test problems were taken from [33] to test this adapted grouping genetic algorithm. Both adapted grouping genetic algorithm and adapted simulated annealing-based heuristic [33] have found the solution with same number of inter-cellular moves for first three test 
J. N. Patel, S. V. Patel; Approaches to solve cell formation, machine layout and cell layout problem: A Review,

Transactions on Machine Learning and Artificial Intelligence, Volume 2 No 5 Oct (2014); pp: 80-96

problems. Adapted grouping genetic algorithm has found the solution with less number of inter-cellular moves compared to adapted simulated annealing-based heuristic for fourth test problem. Improvement compared to the previous works was demonstrated by adapted grouping genetic algorithm \& it was found fast and efficient with all types of data in term of alternative process plans and alternative routings.

\subsubsection{Modified genetic algorithm}

Modified Genetic Algorithm based novel approach was developed in [34] to solve cell formation problem in cellular manufacturing system. Machine utilization, grouping efficiency and grouping efficacy was used as an aggregate performance measure of clustering to evaluate the quality of solution found by the Modified Genetic Algorithm for cell formation. Modified genetic algorithm finds out the better quality solution in most cases compared to rank order clustering [17], original ART1 [35], modified ART1 [36]. Modified genetic algorithm finds out the best results to solve cell-formations problem for most simulated examples, or at least same results as found by modified ART1. Modified Genetic Algorithm shows the ability of generalization to solve cell formation problem [34].

\subsubsection{Hierarchical genetic algorithm}

Hierarchical genetic algorithm was developed in [37] to solve cell formation problem, intracellular machine layout design problem \& cell layout design problem concurrently in cellular manufacturing system. The results generated by hierarchical genetic algorithm were evaluated by taking the six test problems from [38]. The results generated by hierarchical genetic algorithm were compared with two existing methods (TOPSIS-IMP-SAW (TIS) and TOPSIS-IMP-TOPSIS (TIT)) that were proposed in [38]. Comparison of results in terms of grouping efficiency and grouping efficacy showed that hierarchical genetic algorithm outperforms two existing approaches TIS and TIT.

\subsubsection{Simulated annealing}

In [39], a mathematical programming model for the cell formation problem with multiple identical machines, which minimizes the inter-cellular flow, was presented and a simulated annealing algorithm was implemented to solve the problem. A set of problems taken from [40] to test simulated annealing algorithm. A real world case was also solved by simulated annealing algorithm. The efficiency of the model was specified by the computational results, even for large sized problems.

A nonlinear integer model of cell formation problem in dynamic condition was first developed in [4] and then solved by Simulated Annealing is described in 3.2.1. Simulated annealing was developed in [41] to solve cell formation problem in cellular manufacturing system is described in 3.3.3. Simulated Annealing was developed in [13] to solve machine layout problem is described in 3.1.5.

\subsubsection{Ant colony optimization}

In [14], a mathematical model for inter-cell layout problem was developed \& an ant algorithm was developed to solve the problem. The performance of ant algorithm was compared to the facility layout algorithms such as H63 [42], HC63-66 [42], CRAFT [42] and Bubble Search [43] as well as other existing ant colony implementations for QAP such as FANT [44], HAS-QAP [45], MMAS-QAP2-opt [46], and ANTS [47] algorithms. The performance of ant algorithm was also compared with GH Method [48]. Ant algorithm significantly outperforms the facility layout algorithms \& it is effective and efficient as compared to other existing ant algorithms. 
Ant Colony Optimization was developed in [13] to solve machine layout problem is described in 3.1.5.

\subsubsection{Multi-objective scatter search}

A multi-objective scatter search was developed in [49] to solve a dynamic cell formation problem in cellular manufacturing system. Two well-known multi-objective genetic algorithms namely SPEA-II and NSGA-II were implemented in [49] according to their description found from the literature \& they were compared with a multi-objective scatter search based on some comparison metrics and statistical approach. The performance of a multi-objective scatter search was found superior compared to two genetic algorithms.

\subsubsection{Fuzzy relational data clustering algorithm}

A fuzzy relational data clustering algorithm was developed in [50] to solve cell formation problem in cellular manufacturing system. This fuzzy relational data clustering algorithm was found better than mixed-variable fuzzy clustering approach [51] according to the grouping efficiency measure. The fuzzy relational data clustering algorithm is still good to solve cell formation problem where the machine/part matrix has only general numeric data. In total, the fuzzy relational data clustering algorithm presents a realistic solution methodology to solve cell formation problem based on group technology concept, especially when the machine/part matrix has a mixed-variable type with symbolic and fuzzy data.

\subsubsection{Evolutionary algorithm}

Enhanced evolutionary algorithm was developed in [52] to solve cell formation and layout problems together, based on sequence data. This approach capable of producing high quality solutions was based on enhanced group chromosome scheme, group crossover operator, group mutation operator, and a chromosome repair mechanism. It was noted in [52] that increasing the number of cells and/or machines may require more iterations before convergence to a good solution; the solution space was not affected by the number of parts. Parallel mechanism of evolutionary algorithm provides the algorithm robustness and effectiveness over a variety of ill-structured input matrices [52]. Evolutionary algorithm was found more acceptable compared to other heuristics available in the literature.

\subsubsection{Tabu Search}

A nonlinear integer model of cell formation problem in dynamic condition was first developed in [4] and then solved by Tabu Search is described in 3.2.1.

\subsection{Hybrid Methods}

Hybrid methods are formed by combining two methods to solve the problem. An individual method without hybridizing with other method is not able to provide high quality solution in some cases. So, main purpose of hybrid methods is to find out high quality solution of the problem.

\subsubsection{Multi-objective design methodology}

The application of recently developed multi-objective intra-cell layout \& inter-cell layout designs methodologies in a cellular manufacturing was presented in [53] which addressed real time problems from a dynamic food manufacturing and packaging company in Australia. Methodology was developed by hybridizing Non-linear Goal Programming with Simulated Annealing. Layout designs generated by this model were compared with the company existing layout designs. Benefits offered by this model compared to company existing layout design were: safe working environment, $30 \%$ reduced material handling cost, 
J. N. Patel, S. V. Patel; Approaches to solve cell formation, machine layout and cell layout problem: A Review, Transactions on Machine Learning and Artificial Intelligence, Volume 2 No 5 Oct (2014); pp: 80-96

half a million dollars reduction in purchasing bar-coding machines, reduced number of lift-trucks needed, increased employees efficiency and reduced waste.

\subsubsection{New approach hybridizing local search heuristic with genetic algorithm}

A new approach which joins a local search heuristic with a genetic algorithm was developed in [54] to solve cell formation problem in cellular manufacturing system. A set of problems were taken from the literature to test this new approach. The performance of this new approach was found remarkably well. This new approach found solutions that are at least as good as the ones found previously by other methods in the literature. This new approach has improved the previous solutions for $57 \%$ of the problems, in some cases by as much as $12 \%$.

\subsubsection{Hybridizing genetic algorithm with large-scale optimization techniques}

In [55], a complete model which links several known problems in that it joins the cell formation problem, the machine allocation problem, and the part routing problem was presented for designing a cellular manufacturing system \& a hybrid solution methodology which combines genetic algorithm and large-scale optimization techniques was developed to solve large-scale capacitated cell formation problems with multiple routings. A limited computational experiment was conducted which compares the solution quality of this hybrid solution methodology with existing solution methods available in the literature concerning smaller problems taken from the literature. Hybrid solution methodology was found capable to find solutions that are at least as good as solutions given by existing methods available in the literature. A more extensive computational study to assess the practicability and the performance of full-scale approach [55] to solve large-scale problems was conducted. The final solutions found show an improvement of $18-40 \%$ (average $28 \%$ ) over the corresponding reference solutions in regards to the objective function. An opportunity to increase the sampling of the space of solutions without much increasing the CPU time per evaluation was achieved by using local improvement strategy together with other mutation operators. This may increase the change of improving the solution quality by opening up the opportunity to explore more solutions [55].

\subsubsection{Evolutionary algorithm created by hybridizing standard genetic algorithm with local search}

An evolutionary algorithm that improves the efficiency of the standard genetic algorithm by hybridizing it with a local search around some of the solutions it visits and simulated annealing were developed in [41] to solve cell formation problem in cellular manufacturing system. Cell formation problem instances were taken from the literature to assess the performance of both algorithms. Comparison of results of both algorithms with the results of five other algorithms from the literature was presented. Evolutionary method [41] outperformed other Evolutionary algorithms from the literature in solving 8 out of 36 instances of cell formation problem while in solving 26 instances, the solutions generated by Evolutionary method were found same as the best previously known solutions. Not only the best previously known solutions, but also better solutions than previously best known solutions for various problem instances were found by simulated annealing. 


\subsubsection{Hybrid method created by hybridizing steady state genetic algorithm with local search algorithm}

Local Search Algorithm (LSA) and Hybrid Method (HM) were developed in [56] to solve the cell formation problem. Each offspring solution generated with a steady state genetic algorithm was improved by LSA and thus both LSA \& steady state genetic algorithm formed a hybrid method. 35 benchmark problems were selected and solved using LSA \& HM. Average percentage of variation of results generated by LSA with respect to the best known solutions was $1 \%$ in evaluated 35 benchmark problems. Average running time of LSA to solve 35 benchmark problems was reported as 0.64 seconds. Percentage of variation of results generated by $\mathrm{HM}$ with respect to the best-known solutions was $0 \%$ for 31 evaluated benchmark problems out of 35 selected benchmark problems. HM improved the best-known solution of other three benchmark problems $\&$ found $0.01 \%$ bad solution compared to the best-known solution of the last benchmark problem.

\subsubsection{Hybrid meta-heuristic algorithm created by hybridizing genetic algorithm with variable neighborhood search}

A linear fractional programming model for cell formation problem with the objective of maximizing the grouping efficacy was developed in [57] in case the number of cells was not pre-determined. Two test problems were selected from literature to compare the proposed model with the five previous methods which have solved these problems. Comparison showed that this linear fractional programming model outperforms all other methods.

A hybrid meta-heuristic algorithm was developed in [57] in which genetic algorithm and variable neighborhood search (GA-VNS) were combined. 35 test problems from the literature were selected to compare the quality of the solutions of this hybrid meta-heuristic algorithm with 17 previous well-known methods using the grouping efficacy measure. Comparison showed that GA-VNS is a better algorithm for solving the cell formation problem as compared to other methods.

\subsection{Exact solution methods}

Exact solution methods find out the optimum solution of the problem. But they fail to find out the solution of large-sized NP-Complete optimization problems in a practical length of time. They are used to solve small-sized \& medium-sized NP-Complete optimization problems optimally.

\subsubsection{Branch-and-bound approach}

A new nonlinear mixed-integer programming model was presented in [58] for the facility layout problem in a two-dimensional area with the objective of minimizing the total distance traveled by the material in the shop floor, a technique was used to linearize this model \& branch-and-bound approach was developed to optimally solve the proposed mathematical programming model. Comparison of results showed that the total distance traveled by the products was reduced about $41.8 \%$ for small-sized and about $44.8 \%$ for medium-sized problems by this model as compared to the process layouts for the example problems. Large-sized combinatorial optimization problems can't be solved using the exact algorithms in a reasonable time [58]. This limitation is also applicable to the branch-and-bound approach because it is an exact method. This model can also be used to determine the processing route of products in an existing machine layout system with the objective of minimizing the total distance traveled by the material in the shop floor. 
J. N. Patel, S. V. Patel; Approaches to solve cell formation, machine layout and cell layout problem: A Review,

Transactions on Machine Learning and Artificial Intelligence, Volume 2 No 5 Oct (2014); pp: 80-96

\subsubsection{Dinkelbach algorithm}

In [59], the cell formation problem was first converted into an equivalent binary linear fractional programming problem \& then solved using Dinkelbach algorithm where the CPLEX 12.2 Optimizer was utilized to solve the binary linear programming problem at each iteration. Dinkelbach algorithm solved 27 out of the 35 benchmarked problems optimally. Remaining 8 problems out of the 35 benchmarked problems, Dinkelbach algorithm prematurely stopped before getting optimal solution because of memory limit. For these 8 problems average grouping efficacy of best known solutions was found as $0.78 \%$ better than grouping efficacy of the solutions generated by Dinkelbach algorithm. Running time of Dinkelbach algorithm was reported high compared to meta-heuristics.

\section{Analytical review of approaches}

Table 1 presents problem-wise classification table of approaches along with their benefits and drawbacks. To solve each of the three problems namely cell formation, machine layout and cell layout problem, approaches are classified into one of four categories namely heuristics, meta-heuristics, hybrid methods and exact solution methods. Classification also shows whether approaches have solved these three problems individually or jointly.

Table 1: Problem-wise classification table of approaches

\begin{tabular}{|c|c|c|c|}
\hline Problems & Cell Formation Problem & Machine Layout Problem & Cell Layout Problem \\
\hline \multicolumn{4}{|c|}{$\begin{array}{l}\text { Approaches which solve cell formation, machine layout \& cell layout problem individually are further categorized as } \\
\text { per the following. }\end{array}$} \\
\hline Heuristics & $\begin{array}{l}\text { ZODIAC Method, GRAFICS Method, Rank } \\
\text { Order Clustering, Minimum Spanning } \\
\text { Trees-Clustering Algorithm, CASE } \\
\text { Algorithm, Hierarchical Clustering, Linear } \\
\text { Assignment Algorithm, Similarity } \\
\text { Coefficient Methods }\end{array}$ & 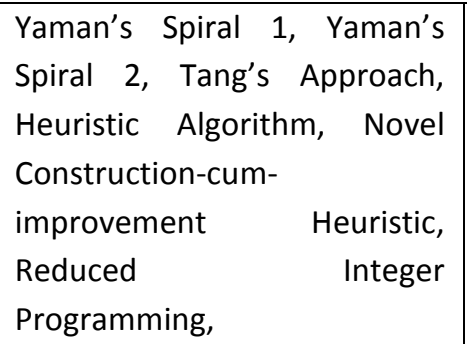 & $\begin{array}{l}\text { H63, HC63-66, CRAFT, } \\
\text { Bubble Search, }\end{array}$ \\
\hline Benefits & \multicolumn{3}{|c|}{$\begin{array}{l}\text { They can solve large-sized NP-Complete Problems efficiently in such situations where exact solution } \\
\text { methods fail to find out the solution of NP-Complete Problems in a practical length of time. }\end{array}$} \\
\hline Drawbacks & \multicolumn{3}{|c|}{$\begin{array}{l}\text { They may not find out optimum solution and sometimes some heuristics may find out solution that } \\
\text { is very far from optimum solution. }\end{array}$} \\
\hline Meta-heuristics & $\begin{array}{l}\text { Genetic Algorithm, Cell Formation - } \\
\text { Grouping Genetic Algorithm, Modified } \\
\text { Genetic Algorithm, Evolutionary } \\
\text { Algorithm, Adapted Grouping Genetic } \\
\text { Algorithm, Enhanced Grouping Genetic } \\
\text { Algorithm, Simulated Annealing, } \\
\text { Adapted Simulated Annealing-based } \\
\text { Heuristic, Tabu Search, Ant Colony } \\
\text { Optimization, Multi-objective Scatter } \\
\text { Search, Greedy Randomized Adaptive } \\
\text { Search Procedure, Water Flow-like } \\
\text { Algorithm, Differential Evolution }\end{array}$ & $\begin{array}{l}\text { Genetic Algorithm, Ant Colony } \\
\text { Optimization, } \quad \text { Simulated } \\
\text { Annealing }\end{array}$ & $\begin{array}{l}\text { Ant Colony } \\
\text { Optimization, Genetic } \\
\text { Hybrid Algorithm }\end{array}$ \\
\hline
\end{tabular}




\begin{tabular}{|c|c|c|c|}
\hline & $\begin{array}{l}\text { Algorithm, Original ART1, Modified } \\
\text { ART1, Fuzzy ART, Fuzzy Relational Data } \\
\text { Clustering Algorithm, Mixed-variable } \\
\text { Fuzzy Clustering Approach }\end{array}$ & & \\
\hline Benefits & \multicolumn{3}{|c|}{$\begin{array}{l}\text { They perform more powerful search compared to heuristics because they have mechanism which } \\
\text { escapes them from trapping into a local minimum \& number of points at once are searched by them } \\
\text { rather than a single point. }\end{array}$} \\
\hline Drawbacks & \multicolumn{3}{|c|}{$\begin{array}{l}\text { Compared to heuristics, they consume more time to find out the solution of large-sized NP-Complete } \\
\text { Problems. }\end{array}$} \\
\hline $\begin{array}{l}\text { Hybrid } \\
\text { Methods }\end{array}$ & $\begin{array}{l}\text { New Approach hybridizing Local Search } \\
\text { Heuristic with Genetic Algorithm, } \\
\text { Simulated Annealing with Variable } \\
\text { Neighborhood, Hybrid Meta-heuristic } \\
\text { Algorithm which combines Genetic } \\
\text { Algorithm with Variable Neighborhood } \\
\text { Search, Hybrid Heuristic Algorithm } \\
\text { employing both the Boltzmann Function } \\
\text { from Simulated Annealing and the } \\
\text { Mutation Operator from the Genetic } \\
\text { Algorithm, Hybrid Approach which } \\
\text { combines Genetic Algorithm with Large- } \\
\text { Scale Optimization Techniques }\end{array}$ & 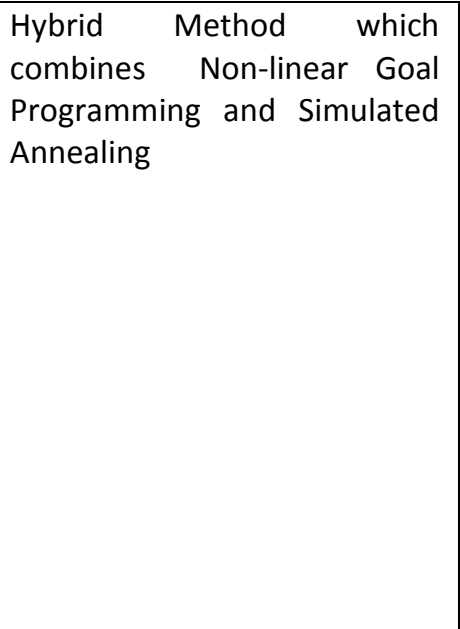 & $\begin{array}{l}\text { Hybrid Method which } \\
\text { combines Non-linear } \\
\text { Goal Programming and } \\
\text { Simulated Annealing }\end{array}$ \\
\hline Benefits & \multicolumn{3}{|c|}{$\begin{array}{l}\text { They find out high quality solution compared to individual heuristics \& individual meta-heuristics } \\
\text { without hybridizing. }\end{array}$} \\
\hline Drawbacks & \multicolumn{3}{|c|}{$\begin{array}{l}\text { Design \& Implementation cost of hybrid methods are high because they created by combining two or } \\
\text { more methods. Compared to individual heuristics \& individual meta-heuristics without hybridizing, } \\
\text { they consume more time to find out the solution. }\end{array}$} \\
\hline $\begin{array}{l}\text { Exact Solution } \\
\text { Methods }\end{array}$ & Dinkelbach Algorithm & Branch-and-Bound Approach & \\
\hline Benefits & \multicolumn{3}{|c|}{ They find out optimum solution of the problem. } \\
\hline Drawbacks & \multicolumn{3}{|c|}{$\begin{array}{l}\text { Compared to heuristics, meta-heuristics \& hybrid methods, they consume much more time to find } \\
\text { out the solution. They may fail to find out the solution of large-sized NP-Complete Problems due to } \\
\text { hardware limitation. }\end{array}$} \\
\hline \multicolumn{4}{|c|}{ Approaches which solve cell formation \& machine layout problem jointly are further categorized as per the following. } \\
\hline Heuristics & \multicolumn{3}{|l|}{ CLASS Algorithm } \\
\hline \multicolumn{4}{|c|}{$\begin{array}{l}\text { Approaches which solve cell formation, machine layout \& cell layout problem jointly are further categorized as per the } \\
\text { following. }\end{array}$} \\
\hline Heuristics & \multicolumn{3}{|l|}{ TOPSIS-IMP-SAW, TOPSIS-IMP-TOPSIS } \\
\hline Meta-heuristics & \multicolumn{3}{|c|}{ Hierarchical Genetic Algorithm, Enhanced Evolutionary Algorithm } \\
\hline
\end{tabular}

It can be clear from the above discussions that most of the researches have solved only cell formation problem whereas many researchers have solved only machine layout problem without first solving cell formation problem. Only few researches have solved cell layout problem \& these three problems completely. In order to generate complete cellular manufacturing system design, three problems namely cell formation, machine layout and cell layout problem should be efficiently solved sequentially. Some researchers have solved these problems concurrently by implementing single approach. While solving two or more problems concurrently requires single approach to be implemented but it also wastes 
J. N. Patel, S. V. Patel; Approaches to solve cell formation, machine layout and cell layout problem: A Review, Transactions on Machine Learning and Artificial Intelligence, Volume 2 No 5 Oct (2014); pp: 80-96

computational time \& may not find out the good quality solution of machine layout \& cell layout problem because cell formation, machine layout and cell layout are sequential step not concurrent in the design of cellular manufacturing system. It makes no sense to start solving machine layout \& cell layout problem without first solving cell formation problem completely.

Genetic algorithm based approaches are given more attention as compared to other approaches to solve cell formation, machine layout and cell layout problem. Here selection of appropriate component of GA is of prime importance. Some researchers have selected the roulette wheel selection which sometimes causes the premature convergence and thus genetic algorithm is not able to find out the global optimum solution. In our opinion use of Rank selection may avoid the premature convergence and leads find out the global optimum solution.

Analysis should be performed on the various mutation rate values to find out the suitable mutation rate value for which genetic algorithm has more chances to find out good quality solution or best solution. If suitable mutation rate value is utilized in subsequent implementation of genetic algorithm then it will improve the performance of resulting genetic algorithm.

Population size \& maximum generation number of genetic algorithm depends on nature \& complexity of problem. Appropriate value of population size \& maximum generation number improves the performance of genetic algorithm. So analysis should be performed to find out how population size \& maximum generation number are related to the nature \& complexity of problem. Analysis is also needed to be performed to find out whether larger population size with less number of generations or smaller population size with large number of generations can improve the performance of genetic algorithm.

\section{Conclusion and Future Research Scope}

In order to achieve higher production efficiency using cellular manufacturing concept compared to traditional manufacturing, Researchers have solved cell formation, machine layout and cell layout problem in cellular manufacturing system by using various approaches. The paper discussed most of these approaches along with existing performance criteria and compared them. Approaches have been classified into one of four categories namely heuristics, meta-heuristics, hybrid methods and exact solution methods and their benefits and drawbacks are reported in this paper. Genetic algorithm based approaches were widely used by researchers to solve cellular manufacturing system problems. Performance of genetic algorithm can still be improved by selecting appropriate components and proper value of parameters of genetic algorithm.

Future research scope in this area is to develop approaches which can improve best-known solutions of cell formation, machine layout and cell layout problem reported in the literature in order to further minimize total manufacturing costs and time of manufacturing industries. Further work in the area can ultimately optimize the performance of industrial manufacturing processes.

\section{REFERENCES}

[1]. M. P. Chandrasekharan, \& R. Rajagopalan, "An ideal seed non-hierarchical clustering algorithm for cellular manufacturing", International Journal of Production Research, vol. 24(2), 1986, pp. 451-463. 
[2]. M. P. Chandrasekharan, \& R. Rajagopalan, “MODROC: an extension to rank order clustering for group technology", International Journal of Production Research, vol. 24(5), 1986, pp. 1221-1233.

[3]. Kumar, C. S., \& Chandrasekharan, M. P., "Grouping efficacy: A quantitative criterion for goodness of block diagonal forms of binary matrices in group technology", International Journal of Production Research, vol. 28(2), 1990, pp. 233-243.

[4]. Tavakkoli-Moghaddam R., Aryanezhad M. B., Safaei N., \& Azaron A., "Solving a dynamic cell formation problem using metaheuristics", Applied Mathematics and Computation, vol. 170(2), 2005, pp. 761-780.

[5]. Vin E., Delchambre A. \& Francq P., "A generalized cell formation problem solved by an adapted GGA", 8 International Conference of Modeling and Simulation - MOSIM'10, May 10-12, 2010.

[6]. McCormick Jr., W. T., Schweitzer, P. J., \& White, T. W., "Problem decomposition and data reorganization by a clustering technique", Operations Research, vol. 20(5), 1972, pp. 993-1009.

[7]. Wang J., "Formation of machine cells and part families in cellular manufacturing systems using a linear assignment algorithm", Automatica, vol. 39(9), 2003, pp. 1607-1615.

[8]. Collette Y, \& Siarry P., “Multi-objective optimization: principles and case studies”, New York: Springer, 2003.

[9]. Mahdavi, I. and Mahadevan, B., "CLASS: An algorithm for cellular manufacturing system and layout design using sequence data", Robotics and Computer-Integrated Manufacturing, vol. 24(3), 2008, pp. 488-497.

[10]. V. Anbumakar and G. Prabhaharan, "Machine assignment in cellular manufacturing layout using genetic algorithm", The International Journal of Applied Management and Technology, vol. 4(1), 2006, pp. 165-179.

[11]. Chan W. M., Chan C. Y. \& Ip W. H., "A heuristic algorithm for machine assignment in cellular layout", Computers \& industrial Engineering, vol. 44, 2002, pp. 49-73.

[12]. I. B. Hunagund \& M. Pillai V, "Development of a heuristic for layout formation and design of robust layout under dynamic demand", Proceedings of the International Conference on Digital Factory, ICDF 2008, August 11-13, 2008 Organized, pp. 1398-1405.

[13]. Andersen R., "Solution methods to the machine layout problem", Doctoral dissertation, Technical University of Denmark, DTU, DK-2800 Kgs. Lyngby, Denmark, 2006.

[14]. Solimanpur M., Vrat P. \& Shankar R., "Ant colony optimization algorithm to the inter-cell layout problem in cellular manufacturing", European Journal of Operational Research, vol. 157(3), 2004, pp. 592-606.

[15]. Yaman.R, Gethin.D.T. and Clarke.M.J., "An effective sorting method for facility layout constructions", International Journal of Production Research, vol. 31(2), 1993, pp. 413-427.

[16]. Tang.C. and Abdel-Malek.L.L., "A frame work for hierarchical interactive generation of cellular layout", International Journal of Production Research, vol. 34(8), 1996, pp. 2133-2162.

[17]. J. R. King, "Machine-component grouping in production flow analysis: an approach using a rank order clustering algorithm", International Journal of Production Research, vol. 18 (2), 1980, pp. 213-232. 
J. N. Patel, S. V. Patel; Approaches to solve cell formation, machine layout and cell layout problem: A Review,

Transactions on Machine Learning and Artificial Intelligence, Volume 2 No 5 Oct (2014); pp: 80-96

[18]. Srinivasan, G., Narendran, T. T., \& Mahadevan, B., "An assignment model for the part-families problem in group technology", International Journal of Production Research, vol. 28(1), 1990, pp. 145-152.

[19]. Yin Y. \& Yasuda K., "Similarity coefficient methods applied to the cell formation problem: a comparative investigation", Computers \& Industrial Engineering, vol. 48(3), 2005, pp. 471-489.

[20]. Ahi A., Aryanezhad M. B., Ashtiani B., \& Makui A., "A novel approach to determine cell formation, intracellular machine layout and cell layout in the CMS problem based on TOPSIS method", Computers \& Operations Research, vol. 36(5), 2009, pp. 1478-1496.

[21]. Morad N., "Genetic Algorithms Optimization for the Machine Layout Problem", International Journal of the Computer, the Internet and Management, vol. 8(1), 2000.

[22]. Mahdavi I., Paydar M. M., Solimanpur M. \& Heidarzade A., "Genetic algorithm approach for solving a cell formation problem in cellular manufacturing", Expert Systems with Applications, vol. 36(3), 2009, pp. 65986604.

[23]. Chandrasekharan, M. P., \& Rajagopalan, R., "ZODIAC: An algorithm for concurrent formation of part-families and machine-cells", International Journal of Production Research, vol. 25(6), 1987, pp. 835-850.

[24]. Srinivasan, G., \& Narendran, T. T., "GRAFICS-A nonhierarchical clustering algorithm for group technology", International Journal of Production Research, vol. 29(3), 1991, pp. 463-478.

[25]. Cheng, C., Gupta, Y., Lee, W., \& Wong, K., “A TSP-based heuristic for forming machine groups and part families", International Journal of Production Research, vol. 36, 1998, pp. 1325-1337.

[26]. Onwubolu, G. C., \& Mutingi, M., "A genetic algorithm approach to cellular manufacturing systems", Computers and Industrial Engineering, vol. 39(1), 2001, pp. 125-144.

[27]. Goncalves, J., \& Resende, M., “An evolutionary algorithm for manufacturing cell formation”, Computers and Industrial Engineering, vol. 47, 2004, pp. 247-273.

[28]. Wu, T. H., Chang, C. C., \& Chung, S. H., “A simulated annealing algorithm for manufacturing cell formation problems", Expert Systems with Applications, vol. 34, 2008, pp. 1609-1617.

[29]. De Lit P., Falkenauer E., \& Delchambre A., “Grouping genetic algorithms: an efficient method to solve the cell formation problem", Mathematics and Computers in simulation, vol. 51(3), 2000, pp. 257-271.

[30]. Brown E. C., \& Sumichrast R. T., "CF-GGA: a grouping genetic algorithm for the cell formation problem", International Journal of Production Research, vol. 39(16), 2001, pp. 3651-3669.

[31]. SRINIVASAN, G., “A clustering algorithm for machine cell formation in group technology using minimum spanning trees", International Journal of Production Research, vol. 32, 1994, pp. 2149-2158.

[32]. JOINES, J., CULBRETH, C. T. and KING, R. E., “Manufacturing cell design: an integer programming model employing genetic algorithms", IEE Transactions, vol. 28, 1996, pp. 69-85.

[33]. Sofianopoulou, S., "Manufacturing cell design with alternative process plans and/or replicate machines", International Journal of Production research, vol. 37(3), 1999, pp. 707-720. 
[34]. Car Z. \& Mikac T., "Evolutionary approach for solving cell-formation problem in cell manufacturing", Advanced Engineering Informatics, vol. 20(3), 2006, pp. 227-232.

[35]. S. J. Chen, \& C. S. Cheng, "A neural network-based cell formation algorithm in cellular manufacturing", The International Journal of Production Research, vol. 33 (2), 1995, pp. 293-318.

[36]. Mikac T, Jurkovic' M, \& Pekic' Z., "A neural network approach in cellular manufacturing”, in: Proceedings of the 5th International Conference on Advanced Manufacturing Systems and Technology, AMST '99, 1999, pp. 521-528.

[37]. K. Chandrasekar, P. Venkumar, "Genetic algorithm approach for integrating cell formation with machine layout and cell layout", International Journal of Operational Research, vol. 16(2), 2013, pp. 155-171.

[38]. Ahi, A., Aryanezhad, M. B., Ashtiani, B. and Makui, A., "A novel approach to determine cell formation, intracellular machine layout and cell layout in the CMS problem based on TOPSIS method", Computers and Operations Research, vol. 36, 2009, pp. 1478-1496.

[39]. Xambre A. R., \& Vilarinho P. M., “A simulated annealing approach for manufacturing cell formation with multiple identical machines", European Journal of Operational Research, vol. 151(2), 2003, pp. 434-446.

[40]. Wu, N., \& Salvendy, G., "An efficient heuristic for the design of cellular manufacturing systems with multiple identical machines", International Journal of Production Research, vol. 37(15), 1999, pp. 3519-3540.

[41]. Pailla A., Trindade A. R., Parada V. \& Ochi L. S., “A numerical comparison between simulated annealing and evolutionary approaches to the cell formation problem", Expert Systems with Applications, vol. 37(7), 2010, pp. 5476-5483.

[42]. Nugent, C. E., Vollman, T. E., \& Ruml, J., “An experimental comparison of techniques for the assignment of facilities to locations", Operations Research, vol. 16(1), 1968, pp. 150-173.

[43]. Wang, S., \& Sarker, B. R., "Locating cells with bottleneck machines in cellular manufacturing systems", International Journal of Production Research, vol. 40 (2), 2002, pp. 403-424.

[44]. Taillard, E. D., \& Gambardella, L. M., “Adaptive memories for the quadratic assignment problem”, Technical Report IDSIA-87-97, IDSIA, Lugano, Switzerland, 1997.

[45]. L. M. Gambardella, E. Taillard, and M. Dorigo, “Ant colonies for QAP," IDSIA, Lugano, Switzerland, Technical Report IDSIA 97-4, 1997.

[46]. Stutzle, T., \& Hoos, H. H., “MAX-MIN ant system”, Future Generation Computer Systems, vol. 16(8), 2000, pp. 889-914.

[47]. Maniezzo, V., \& Colorni, A., "The ant system applied to the quadratic assignment problem", IEEE Transactions on Knowledge and Data Engineering, vol. 11 (5), 1999, pp. 769-778.

[48]. C. Fleurent, J. A. Ferland, "Genetic hybrids for the quadratic assignment problem", in: P.M. Pardalos, H. Wolkowicz (Eds.), Quadratic Assignment and Related Problems, DIMACS Series on Discrete Mathematics and Theoretical Computer Science, vol. 16, American Mathematical Society, Providence, RI, 1994, pp. $173-187$. 
J. N. Patel, S. V. Patel; Approaches to solve cell formation, machine layout and cell layout problem: A Review, Transactions on Machine Learning and Artificial Intelligence, Volume 2 No 5 Oct (2014); pp: 80-96

[49]. Bajestani M. A., Rabbani M., Rahimi-Vahed A. R. \& Baharian Khoshkhou G., "A multi-objective scatter search for a dynamic cell formation problem", Computers \& operations research, vol. 36(3), 2009, pp. 777-794.

[50]. Hung W. L., Yang M. S. \& Lee E. S., “Cell formation using fuzzy relational clustering algorithm”, Mathematical and computer Modelling, vol. 53(9), 2011, pp. 1776-1787.

[51]. M. S. Yang, W. L. Hung, \& F. C. Cheng, "Mixed-variable fuzzy clustering approach to part family and machine cell formation for GT applications", International Journal of Production Economics, vol. 103(1), 2006, pp. 185198.

[52]. Mutingi M., Mbohwa C. T., Mhlanga S., \& Goriwondo W., “Integrated Cellular Manufacturing System Design: an Evolutionary Algorithm Approach", Proceedings of the 2012 International Conference on Industrial Engineering and Operations Management, July 3 -6, 2012, pp. 254-264.

[53]. Bazargan-Lari.M., "Layout designs in cellular manufacturing”, European Journal of Operational Research, vol. 112, 1999, pp. 258-272.

[54]. Gonçalves J. F. \& Resende M. G., "An evolutionary algorithm for manufacturing cell formation”, Computers \& Industrial Engineering, vol. 47(2), 2004, pp. 247-273.

[55]. Nsakanda A. L., Diaby M. \& Price W. L., “Hybrid genetic approach for solving large-scale capacitated cell formation problems with multiple routings", European Journal of Operational Research, vol. 171(3), 2006, pp. 1051-1070.

[56]. Elbenani B., Ferland J. A., \& Bellemare J., "Genetic algorithm and large neighbourhood search to solve the cell formation problem", Expert Systems with Applications, vol. 39(3), 2012, pp. 2408-2414.

[57]. Paydar M. M., \& Saidi-Mehrabad M., "A hybrid genetic-variable neighborhood search algorithm for the cell formation problem based on grouping efficacy", Computers \& Operations Research, vol. 40(4), 2013, pp. 980990.

[58]. Maghsud Solimanpur and Amir Jafari, "Optimal solution for the two-dimensional facility layout problem using a branch-and-bound algorithm", Computers \& Industrial Engineering, vol. 55(3), 2008, pp. 606-619.

[59]. Elbenani, B., \& Ferland, J. A., "Cell Formation Problem Solved Exactly with the Dinkelbach Algorithm", Publication CIRRELT-2012-07, University of Montreal, Canada, 2012. 